DOI: $10.15593 / 2224-9826 / 2015.3 .03$

УДК 658.345

\title{
В.А. Сенченко
}

\author{
Волгоградский центр охраны труда и экологии, Волгоград, Россия
}

\section{ПРОБЛЕМЫ ЭФФЕКТИВНОСТИ ОБУЧЕНИЯ ТРЕБОВАНИЯМ ОХРАНЫ ТРУДА НА МАЛЫХ ПРЕДПРИЯТИЯХ СТРОИТЕЛЬНОЙ ОТРАСЛИ}

\begin{abstract}
Объектом исследования является эффрективность обучения работников требованиям охраны труда на малых предприятиях строительной отрасли. Проанализирована действующая система обучения требованиям охраны труда в Российской Федерации. В учебных организациях, которые находятся на территории г. Волгограда, был проведен мониторинг программ обучения требованиям охраны труда методом опроса предлагаемых учебных программ обучению по вопросам охраны труда. Мониторинг показал, что учебные программы, по которым проводится обучение по охране труда, имеют межотраслевой характер. В учебных программах, нет специального раздела о требованиях безопасности в строительной отрасли. По результатам мониторинга сделан вывод, что обучение по охране труда в специализированных учебных организациях не учитывает специфику строительной отрасли. А поскольку на малых предприятиях в строительной отрасли с численностью персонала до 50 человек не предусмотрена должность специалиста по охране труда и малые предприятия практически выпадают из внешнего контроля органами государственного надзора, то основной поток знаний о требованиях и культуре безопасности труда при производстве работ несут руководители и специалисты. Если же руководители и специалисты строительных организаций в учебных комбинатах не получили необходимых знаний о специальных требованиях безопасности и культуры безопасности труда при производстве строительных работ, то они не могут донести достоверных знаний о производственных рисках и требованиях безопасности на рабочих местах до своих работников. Таким образом, действующая система обучения требованиям охраны труда на малых предприятиях строительной отрасли становится малоэффективной. С целью повышения эффективности обучения на малых предприятиях строительной отрасли предложено закрепить отраслевой порядок обучения требованиям охраны труда в строительной отрасли. В типовые программы обучения требований охраны труда добавить раздел культура безопасности труда в строительстве.

Ключевые слова: охрана труда в строительной отрасли, обучение требованиям охраны труда, охрана труда на малых предприятиях, культура безопасности труда.
\end{abstract}




\title{
V.A. Senchenko
}

\author{
Volgograd Center of Labor Protection and Ecology, \\ Volgograd, Russian Federation
}

\section{LEARNING EFFICIENCY PROBLEMS TO REQUIREMENTS OF LABOR PROTECTION AT SMALL ENTERPRISES OF CONSTRUCTION BRANCH}

\begin{abstract}
Object of research is learning efficiency of workers to requirements of labor protection at small enterprises of construction branch. The operating system of training in requirements of labor protection in the Russian Federation is analysed. In the educational organizations which are in the territory of Volgograd, monitoring of programs of training in requirements of labor protection was made. Monitoring was carried out by method of poll of the offered training programs to training concerning labor protection. Monitoring showed that training programs on which to be provided training on labor protection have interindustry character. In training programs, there is no special section on safety requirements in construction branch. By results of monitoring the conclusion is drawn that training on labor protection in the specialized educational organizations doesn't consider specifics of construction branch. And as at small enterprises in construction branch numbering personnel up to 50 people the position of the labor protection specialist and small enterprises practically isn't provided drop out of external control of the state supervision by bodies, the main stream of knowledge of requirements and culture of safety of work at works is born by heads and experts. And if heads and specialists of the construction organizations in educational combines didn't gain necessary knowledge of special safety requirements and culture of safety of work by production of construction works, they can't inform reliable knowledge of production risks and safety requirements on workplaces to the workers. Thus, the operating system of training in requirements of labor protection at small enterprises of construction branch to become ineffective. For the purpose of increase of learning efficiency at small enterprises of construction branch it is offered to fix a branch order of training in requirements of labor protection in construction branch. In standard programs of training of requirements of labor protection to add the section culture of safety of work in construction.
\end{abstract}

Keywords: protection of work in construction branch, training in requirements of labor protection, labor protection at small enterprises, culture of safety of work.

Согласно ст. $225^{1}$ все работники организации, в том числе руководители, обязаны проходить обучение по охране труда и проверку знаний требований охраны труда в порядке, установленном уполномоченным Правительством России федеральным органом исполнительной власти.

В целях реализации этой нормы совместным Постановлением Минтруда России и Минобразования России от 13.01.2003 утвержден Порядок обучения по охране труда и проверки знаний требований охраны труда работников организаций [1]. Данным нормативным актом установлены единые требования к проведению инструктажей по охра-

${ }^{1}$ Трудовой кодекс Российской Федерации от 30.12.2001 г. № 197-Ф3 // «Консультант плюс»: Региональный информационный центр. URL: http://www.infocom.su (дата обращения: 02.03.2015 г.). 
не труда, обучению работников рабочих профессий, а также руководителей и специалистов, проверке знаний требований охраны труда.

Согласно этому нормативному акту все работники организации проходят обучение по охране труда: при поступлении на работу в течение первого месяца и периодически не реже одного раза в три года в процессе работы.

Обучение по охране труда и проверка знаний требований охраны труда может проводиться в обучающих организациях и непосредственно в организациях по месту работы обучаемого персонала. В соответствии с Указанием Минздравсоцразвития России с 1 декабря 2010 г. проведением обучения по охране труда, как и оказанием прочих услуг по охране труда, могут заниматься только организации, прошедшие соответствующую аккредитацию Минздравсоцразвития России. По состоянию на 24.04.2015 в Реестре аккредитованных организаций числится 2156 организаций, которые занимаются проведением обучения по охране труда [2].

При аккредитации не отмечается отраслевая направленность проводимого аккредитованной организацией обучения по охране труда. К примеру, в Волгоградской области имеют аккредитацию на право обучения по охране труда 38 организации. Из них на территории г. Волгограда находятся 28 организаций.

В учебных организациях, которые находятся на территории г. Волгограда, был проведен мониторинг программ обучения требованиям охраны труда. Во всех учебных центрах был задан один вопрос: по каким программам обучения требованиям охраны труда проводится обучение, есть ли специфический раздел в программе обучения - требования безопасности для строителей. Результат приведен в таблице.

Перечень учебных центров в г. Волгограде, где проводился мониторинг программ обучения требованиям охраны труда

\begin{tabular}{|c|c|c|}
\hline $\begin{array}{l}\text { № } \\
\Pi / \Pi \\
\end{array}$ & Наименование организации & $\begin{array}{c}\text { Почтовый адрес/телефон } \\
\text { организации }\end{array}$ \\
\hline 1 & $\begin{array}{l}\text { Некоммерческое негосударственное образова- } \\
\text { тельное учреждение дополнительного профессио- } \\
\text { нального образования (повышения квалификации) } \\
\text { специалистов «Дом науки и техники» }\end{array}$ & $\begin{array}{l}400005, \text { Волгоградская } \\
\text { область, г. Волгоград, } \\
\text { ул. Глазкова, } 14\end{array}$ \\
\hline 2 & $\begin{array}{l}\text { Негосударственное некоммерческое образова- } \\
\text { тельное учреждение дополнительного профессио- } \\
\text { нального образования (повышения квалификации } \\
\text { специалистов) «Учебный центр „Полипроф М“» }\end{array}$ & $\begin{array}{l}400075, \text { Волгоградская } \\
\text { область, г. Волгоград } \\
\text { ст. Бетонная, } \\
\text { проезд Таймырский, д. } 4\end{array}$ \\
\hline
\end{tabular}


Окончание таблицы

\begin{tabular}{|c|c|c|}
\hline $\begin{array}{l}\text { № } \\
\text { П/П }\end{array}$ & Наименование организации & $\begin{array}{c}\text { Почтовый адрес/телефон } \\
\text { организации }\end{array}$ \\
\hline 3 & $\begin{array}{l}\text { Государственное образовательное автономное } \\
\text { учреждение Волгоградской области «Волгоград- } \\
\text { ский государственный учебно-курсовой комби- } \\
\text { нат» Комитета по строительству и жилищно- } \\
\text { коммунальному хозяйству администрации Волго- } \\
\text { градской области }\end{array}$ & $\begin{array}{l}\text { 400131, Волгоградская об- } \\
\text { ласть, г. Волгоград, } \\
\text { ул. Голубинская, } 1 \\
\end{array}$ \\
\hline 4 & $\begin{array}{l}\text { Негосударственное образовательное учреждение } \\
\text { дополнительного профессионального образования } \\
\text { (повышения квалификации) специалистов «Учеб- } \\
\text { но-курсовой комбинат „Профессия“» }\end{array}$ & $\begin{array}{l}\text { 400064, Волгоградская об- } \\
\text { ласть, г. Волгоград, ул. } \\
\text { Вершинина, д. } 34\end{array}$ \\
\hline 5 & $\begin{array}{l}\text { Негосударственное образовательное учреждение } \\
\text { дополнительного профессионального образования } \\
\text { (повышения квалификации) «Учебный центр» }\end{array}$ & $\begin{array}{l}\text { 400048, Волгоградская об- } \\
\text { ласть, г. Волгоград, пр. им. } \\
\text { маршала Советского Союза } \\
\text { Г.К. Жукова, } 112\end{array}$ \\
\hline 6 & Волгоградская торгово-промышленная палата & $\begin{array}{l}\text { 400005, Волгоградская об- } \\
\text { ласть, г. Волгоград, ул. 7-я } \\
\text { Гвардейская, } 2\end{array}$ \\
\hline 7 & $\begin{array}{l}\text { Негосударственное образовательное учреждение } \\
\text { дополнительного профессионального образования } \\
\text { «Учбный центр „Профобразование“» }\end{array}$ & $\begin{array}{l}\text { 400074, Волгоградская об- } \\
\text { ласть, г. Волгоград, ул. Бар- } \\
\text { рикадная, } 1 \text { д, оф. } 115\end{array}$ \\
\hline 8 & ООО «Нижневолжский центр обучения» & $\begin{array}{l}\text { 400078, Волгоградская об- } \\
\text { ласть, г. Волгоград, пр. им. } \\
\text { В.И. Ленина, 100, оф. } 421\end{array}$ \\
\hline 9 & $\begin{array}{l}\text { ООО «Учебный центр дополнительного профес- } \\
\text { сионального образования специалистов (повыше- } \\
\text { ния квалификации),„Профессия“» }\end{array}$ & $\begin{array}{l}\text { 400105, Волгоградская об- } \\
\text { ласть, г. Волгоград, } \\
\text { ул. Богунская, } 8, \text { оф. } 521\end{array}$ \\
\hline 10 & $\begin{array}{l}\text { Государственное автономное образовательное } \\
\text { учреждение Волгоградской области «Волгоград- } \\
\text { ский государственный учебно-курсовой комби- } \\
\text { нат» }\end{array}$ & $\begin{array}{l}\text { 400131, Волгоградская об- } \\
\text { ласть, г. Волгоград, } \\
\text { ул. Голубинская, } 1\end{array}$ \\
\hline 11 & $\begin{array}{l}\text { Негосударственное образовательное частное уч- } \\
\text { реждение дополнительного профессионального } \\
\text { образования (повышения квалификации) специа- } \\
\text { листов «Региональный учебный центр» }\end{array}$ & $\begin{array}{l}\text { 400131, Волгоградская об- } \\
\text { ласть, г. Волгоград } \\
\text { ул. Коммунистическая, 28a }\end{array}$ \\
\hline 12 & $\begin{array}{l}\text { Автономная некоммерческая организация «Учеб- } \\
\text { но-методический центр „Безопасность труда“»» }\end{array}$ & $\begin{array}{l}400005, \text { Волгоградская об- } \\
\text { ласть, г. Волгоград, } \\
\text { ул. Коммунистическая, } 21\end{array}$ \\
\hline 13 & $\begin{array}{l}\text { Негосударственное образовательное частное уч- } \\
\text { реждение дополнительного образования «Нижне- } \\
\text { волжский центр обучения» }\end{array}$ & $\begin{array}{l}\text { 400078, Волгоградская об- } \\
\text { ласть, г. Волгоград, пр. им. } \\
\text { В.И. Ленина }\end{array}$ \\
\hline 14 & ООО «Центр профессионального обучения» & $\begin{array}{l}\text { 400005, Волгоградская об- } \\
\text { ласть, г. Волгоград, } \\
\text { ул. Дымченко, д. } 186\end{array}$ \\
\hline
\end{tabular}


Мониторинг был проведен в 14 организациях из 28 имеющих аккредитацию в г. Волгограде. Мониторинг показал, что обучение проводится в основном по программе обучения и проверки знаний требований охраны труда для руководителей и специалистов. Программ обучения требованиям охраны труда для руководителей, специалистов и работников строительной отрасли при проведении мониторинга не выявлено. В учебных программах, которые были предложены, нет специального раздела о требованиях безопасности в строительной отрасли. Учебные программы имеют межотраслевой характер.

По данным [3] снижение травматизма на предприятиях строительной отрасли способствует изменение отношения работников к организации охраны труда на собственных предприятиях. Повышение культуры безопасности труда является фактором повышения эффективности системы управления охраной труда в строительстве. В вышеуказанных учебных центрах в программах обучения отсутствуют разделы, посвященные культуре безопасности труда на предприятии. В условиях действующего законодательства донести основы культур безопасности труда возможно через обучения требованиям охраны труда в специализированных организациях.

Таким образом, в учебных комбинатах проходят обучение руководители и специалисты строительной отрасли по программам обучения межотраслевого характера, и специальные требования безопасности труда в строительной отрасли не доводятся до слушателей, что значительно снижает эффективность обучения руководителей и специалистов строительных профессий.

Поскольку на малых предприятиях в строительной отрасли с численностью персонала до 50 человек не предусмотрена должность специалиста по охране труда ${ }^{1}$ и малые предприятия практически выпадают из внешнего контроля органами государственного надзора [7], то основной поток знаний о требованиях и культуре безопасности труда при производстве строительных работ несут руководители и специалисты. При этом если руководители и специалисты строительных организаций не получили необходимых знаний о специальных требованиях безопасности и культуры безопасности труда при производстве строи-

${ }^{1}$ Трудовой кодекс Российской Федерации от 30.12.2001 г. № 197-Ф3 // «Консультант плюс»: Региональный информационный центр. URL: http://www.infocom.su (дата обращения: 02.03.2015 г.). 
тельных работ в учебных комбинатах, то они не донесут достоверных знаний о производственных рисках и требованиях безопасности на рабочих местах до своих работников. Они не могут эффективно контролировать выполнение требований безопасности, если они сами их точно не знают.

Таким образом, система обучения требованиям охраны труда на малых предприятиях строительной отрасли становится малоэффективной.

Также в п. 1.3 действующего Порядка обучения [2] сказано, что в отдельных отраслях экономики, где имеются специфические особенности, органы исполнительной власти могут устанавливать дополнительные требования к организации и проведению обучения по охране труда и проверке требований охраны труда.

Как показал мониторинг, данный пункт не учитывается при составлении программ обучения работников требованиям охраны труда.

В то же время в отрасли имеется достаточный опыт в этом деле. Так, еще в 1995 г. Постановлением Минстроя России был введен в действие СП 12-131-95 «Безопасность труда в строительстве. Примерное Положение о Порядке обучения и проверки знаний по охране труда руководящих работников и специалистов строительства и промышленности строительных материалов».

В дальнейшем в развитие вышеуказанного Порядка с учетом СП 12-131-95 были подготовлены и изданы массовым тиражом следующие документы:

- МДС 12-26.2006 «Методическое пособие по проведению проверки знаний требований охраны труда руководящих работников и специалистов строительных организаций»;

- МДС 12-27.2006 «Методическое пособие по проведению обучения по охране труда руководящих работников и специалистов строительных организаций».

Указанные документы были подготовлены в развитие Типовых учебных планов и Типовой программы обучения по охране труда и проверки знаний требований охраны труда руководителей и специалистов строительных организаций, которые были рекомендованы к применению Решением Центральной аттестационной комиссии по охране труда в строительстве (Протокол от 12.12.2005 № 1). 
По данным $[4,6]$ строительная отрасль является одно из наиболее травмоопасных в Российской Федерации ${ }^{2}$. Следует отметить, что большая часть несчастных случаев в строительной отрасли связана с недостатками организационного характера, что указывает на недостаточные знание требований безопасности.

Производство строительных работ сопряжено с воздействием опасных факторов, которые невозможно устранить полностью или уменьшить степень их воздействия на работника до нормативных значений. Поэтому одной из задач, касающейся сохранения жизни, здоровья и безопасности и содействующей исправлению неблагоприятных ситуаций в строительной отрасли, является повышение эффективности системы управления охраной труда на предприятии $[4,8]$, а также системы обучения требованиям охраны труда [5].

Поскольку строительная отрасль является одной из травмоопасных отраслей народного хозяйства, то для повышения качества обучения требованиям охраны труда и соответственно снижения производственного травматизма необходимо:

1. На федеральном уровне обновить и утвердить типовые программы обучения требованиям охраны труда для руководителей, специалистов и работников строительных профессий.

2. Необходимо в законодательном порядке внести дополнения в Порядок обучения требованиям охраны труда [1] об обязательности обучения руководителей, специалистов и работников наиболее травмоопасных отраслей экономики (в том числе и строительной отрасли) по типовым отраслевым программам обучения требованиям охраны труда.

3. В типовые программы обучения требованиям охраны труда добавить раздел, освещающий вопросы культуры безопасности труда при производстве строительных работ.

Тогда руководители, специалисты и работники малых предприятий строительной отрасли будут получать все необходимые знания о производственных рисках и требованиях безопасности, а не общие положения законодательства об охране труда.

${ }^{2}$ Письмо Росстат №1199/ОГ от 29.07.2014 года «Распределение пострадавших по основным видам происшествий, приведших к несчастному случаю, и структура основных видов происшествий в Российской Федерации за 2013 год». 


\section{Библиографический список}

1. Сенченко В.А. Обучение по охране труда и проверка знаний требований охраны труда работников организаций // Секретарь - референт. -2015 . - № 1 .

2. Реестр аккредитованных организаций оказывающих услуги в области охраны труда [Электронный ресурс]. - URL: http://akot.rosmintrud.ru/ot/organizations (дата обращения: 24.04.2015).

3. Ефимова Е.И. Культура безопасности труда как средство повышения эффективности системы управления охраной труда в строительной отрасли // Интернет-журнал «Науковедение». - 2013. - № 1.

4. Волкова Н.В., Ефимова Е.И. Проблемы обеспечения охраны труда в строительной отрасли // Интернет-журнал «Науковедение». 2013. - Вып. 1.

5. Карауш С.А., Герасимова О.О. Повышение эффективности обучения работников строительной отрасли охране труда за счет мотивации работодателей // Интернет-вестник ВолгГАСУ. Серия: Политематическая. - 2015. - Вып. 1(37). - Ст. 6. - URL: http://www.vestnik.vgasu.ru.

6. Карауш С.А., Герасимова О.О. Причины травматизма и пути его снижения в технологиях строительного производства // Вестник ТГАСУ. - 2012. - № 4. - С. 243-248.

7. Сенченко В.А. Проблемы внешнего контроля состояния условий и охраны труда на малых предприятиях строительной отрасли // Вестник Волгоградского государственного архитектурно-строительного университета. Серия: Строительство и архитектура. - 2013. Вып. 30 (49). - С. 269-274.

8. Сенченко В.А. Совершенствование системы управления охраной труда на предприятиях строительной отрасли со среднесписочной численностью работников до 50 человек // Интернет-вестник ВолгГАСУ. Серия: Политематическая. - 2013. - Вып. 1(25). - URL: http://vestnik.vgasu.ru/attachments/Senchenko-2013_1(25).pdf.

\section{References}

1. Senchenko V.A. Obuchenie po okhrane truda i proverka znanii trebovanii okhrany truda rabotnikov organizatsii [Education on labor protection and examination requirements of the protection of workers organizations]. Sekretar' - referent, 2015, no. 1. 
2. Reestr akkreditovannykh organizatsii okazyvaiushchikh uslugi $\mathrm{v}$ oblasti okhrany truda [The register of accredited organizations providing services in the field of labor], available at: http://akot.rosmintrud.ru/ ot/organizations (accessed: 24 April 2015).

3. Efimova E.I. Kul'tura bezopasnosti truda kak sredstvo povysheniia effektivnosti sistemy upravleniia okhranoi truda v stroitel'noi otrasli [Safety culture as a means to improve the efficiency of the OSH management system in the construction industry]. Internet-zhurnal "Naukovedenie", 2013, no. 1 .

4. Volkova N.V., Efimova E.I. Problemy obespecheniia okhrany truda $\mathrm{v}$ stroitel'noi otrasli [Problems of labor protection in the construction industry]. Internet-zhurnal "Naukovedenie", 2013, vol. 1.

5. Karaush S.A., Gerasimova O.O. Povyshenie effektivnosti obucheniia rabotnikov stroitel'noi otrasli okhrane truda za schet motivatsii rabotodatelei [Increasing the effectiveness of the training of construction workers labor protection at the expense of employers motivation]. Internetvestnik VolgGASU. Seriia "Politematicheskaia", 2015, vol. 1(37), st. 6, available at: http://www.vestnik.vgasu.ru.

6. Karaush S.A., Gerasimova O.O. Prichiny travmatizma i puti ego snizheniia $\mathrm{v}$ tekhnologiiakh stroitel'nogo proizvodstva [Causes of injuries and ways to decrease in construction production]. Vestnik TGASU, 2012, no. 4, pp. 243-248.

7. Senchenko V.A. Problemy vneshnego kontrolia sostoianiia uslovii I okhrany truda na malykh predpriiatiiakh stroitel'noi otrasli [Problems of external monitoring of working conditions and safety in small enterprises of the construction industry]. Vestnik Volgogradskogo gosudarstvennogo arkhitekturno-stroitel'nogo universiteta. Seriia “Stroitel'stvo i arkhitektura, 2013, vol. 30 (49), pp. 269-274.

8. Senchenko V.A. Sovershenstvovanie sistemy upravleniia okhranoi truda na predpriiatiiakh stroitel'noi otrasli so srednespisochnoi chislennost'iu rabotnikov do 50 chelovek [Improving the OSH management system in the enterprises of the construction industry with an average number of employees up to 50 people]. Internet-vestnik VolgGASU. Seriia "Politematicheskaia", 2013, vol. 1(25), available at: http://vestnik.vgasu.ru/ attachments/Senchenko-2013_1(25).pdf.

Получено 08.06.2015 


\section{Об авторе}

Сенченко Владимир Александрович (Волгоград, Россия) - ведущий специалист по охране труда Волгоградского центра охраны труда и экологии (400131, г. Волгоград, ул. Донецкая, 7-142, e-mail: Vladimir_senchenko@vlg.south.rt.ru).

\section{About the author}

Vladimir A. Senchenko (Volgograd, Russian Federation) - Labor protection senior specialist, Volgograd Center of Labor Protection and Ecology (142-7, Donetskaya st., Volgograd, 400131, Russian Federation, e-mail: Vladimir_senchenko@vlg.south.rt.ru). 